\title{
Ensino história indígena em livros didáticos: problematizações a partir de uma coletânea distribuída na rede municipal de ensino de Florianópolis, SC
}

\author{
Teaching indigenous history in textbooks: problematizing a \\ textbook collection used in municipal schools in the city of \\ Florianopolis, SC
}

Sandor Bringmann ${ }^{1}$

DOI: http://dx.doi.org/10.20435/tellus.vi44.708

\begin{abstract}
Resumo: O presente artigo tem como intuito contribuir com algumas reflexões acerca do ensino de História Indígena na Educação Básica a partir da análise e problematização dos conteúdos presentes na coletânea didática Vontade de Saber: História, distribuída a escolas da rede municipal de educação de Florianópolis-SC. A análise fundamenta-se em dispositivos legais, como a Lei $n$. 11645/08, as Diretrizes Operacionais para a Implementação da História e das Culturas dos Povos Indígenas na Educação Básica (2016) e nas normativas do Programa Nacional do Livro e do Material Didático (PNLD). A problematização dos conteúdos e as indicações propositivas foram orientadas pelos princípios teórico-metodológicos da chamada Nova História Indígena, cujos preceitos vêm influenciando a produção historiográfica na área ao longo dos últimos 25 anos, promovendo olhares e práticas que ressaltam e valorizam o protagonismo indígena e sua agência histórica.
\end{abstract}

Palavras-chave: ensino de História; Nova História Indígena; livros didáticos; Ensino Fundamental.

Abstract: The present study aims at contributing to discussions regarding the teaching of indigenous history during compulsory education departing from the analysis and problematization of the contents presented in the textbook collection Vontade de Saber: História, distributed to municipal schools in Florianopolis, Santa Catarina. The analysis is based on legislation such as the law n. 11645/08, the document Operational Guidelines for the Implementation of History and Culture of Indigenous Communities in Compulsory Education (2016), and the normatives proposed in the Programa Nacional do Livro $e$ do Material Didático (PNLD). The problematization of the contents in the textbooks and their corresponding proposals were guided by the theoreticalmethodological principles derived from the New Indigenous History, that has been influencing historiographic production in the area in the last 25 
years, promoting views and practices that highlight and value the indigenous protagonism and their historical agency.

Keywords: teaching of history; new indigenous history; textbooks; elementary school.

\section{INTRODUÇÃO}

A renovação do cenário historiográfico brasileiro, que vem ocorrendo pelo menos desde a década de 1970, promoveu o surgimento de abordagens inovadoras sobre vários temas. Novas perspectivas teóricas e conceituais, a diversificação das fontes e a interlocução de historiadores com outras áreas das ciências sociais possibilitaram a inclusão de novos atores sociais no cenário historiográfico brasileiro. Entre estes novos atores sociais destacam-se os povos indígenas, cujo protagonismo, como lembra Maria Regina Celestino de Almeida, passou a ser mais valorizado pelos historiadores apenas na década de 1990 (ALMEIDA, 2017, p. 18). A nova perspectiva sobre a História Indígena, que ficou conhecida como Nova História In dígena ${ }^{1}$, é fruto de um esforço intelectual e político oriundo de várias frentes, com o objetivo de romper com narrativas predominantes na historiografia nacional (muitas vezes preconceituosas e discriminatórias) e continuamente alimentadas pela mídia e pelas narrativas históricas em escolas, colégios e universidades e incorporadas no imaginário da população brasileira, com imensos prejuízos para todos, mas principalmente para os índios (ALMEIDA, 2017, p. 18-20).

Também remonta à década de 1990 a ampliação da pressão dos diversos movimentos sociais do Brasil e de organizações internacionais para o incremento de ações de combate ao racismo, à intolerância e à xenofobia nos currículos escolares. As reformas curriculares passam a contribuir de forma efetiva para questionar e combater um modelo de ensino de história calcado no padrão masculino, branco, cristão e orientado pelo pensamento eurocêntrico (BITTENCOURT, 2018, p. 108). Entre os resultados práticos dessa mobilização

\footnotetext{
1 Aqui faço menção a estudos clássicos que analisam a presença e forma como é abordada a temática indígena na historiografia brasileira, procurando ressaltar a sua "agência" como sujeitos ativos dos processos históricos e não como vítimas passivas de um enredo colonizador. Exemplos destas abordagens podem ser vistos em Cunha (1992), Monteiro (1994; 2001) e Almeida (2010; 2017).
} 
está a promulgação dos Parâmetros Curriculares Nacionais (PCNs), em 1997, onde a temática da pluralidade cultural ganha destaque em capítulo específico. É importante salientar que os PCNs, enquanto política pública de orientação curricular, são marcados por um "arcabouço estrutural configurado nas relações do Estado com a sociedade civil onde as demandas e pressões exercidas pelo conjunto dos cidadãos associam-se aos interesses de ordem econômica e política definindo linhas de ações institucionais" (SANTIAGO, 2000, p. 3). Desse modo, os PCNs podem ser compreendidos, como parte de uma reforma educacional em sua origem, atendendo as demandas do estado, dos movimentos sociais e da sociedade civil organizada.

Já nos anos 2000, algumas lacunas históricas no âmbito do ensino de História e Cultura Africana, Afro-Brasileira e Indígena, começam a ser preenchidas, especialmente a partir da promulgação da Lei n. 10639 (BRASIL, 2003), das Diretrizes Curriculares Nacionais para a Educação das Relações Étnico-Raciais (BRASIL, 2004) e para o Ensino de História e Cultura Afro-Brasileira e Africana, em 2004, e da Lei n. 11645, em 2008². Tanto a Lei n. 10639/03 quanto a Lei n. 11645/08 são frutos de grande luta por parte dos movimentos negro e indígena, por setores progressistas da política nacional, por universidades, por organizações indigenistas, entre outros. No caso da Lei n. 11645/08, pode-se dizer que as raízes foram estabelecidas com o surgimento de um movimento indígena organizado ainda na década de 1970, o qual alcançou conquistas importantes na Constituição de 1988 (CF88), que reverberaram na Lei de Diretrizes e Bases da Educação Nacional (LDBEN) e nos Parâmetros Curriculares Nacionais (PCNs) (BANIWA, 2007; MUNDURUKU, 2012). Neste contexto, surgem as demandas por uma educação específica, diferenciada e intercultural por parte dos indígenas, conquistadas em parte com as políticas de ações afirmativas promovidas durante o período em que o Brasil foi governado pelo Partido dos Trabalhadores (PT, 2003-2016), que possibilitaram a entrada de indígenas nas universidades públicas e a formação de professores indígenas em nível superior, fortalecendo ainda mais seu protagonismo e visibilidade nos mais diversos setores da sociedade.

2 Esta lei altera a Lei n. 9394/96 (Lei de Diretrizes e Bases da Educação Nacional) e modifica a Lei n= 10.639/03, incluindo no currículo oficial da rede de ensino, além da obrigatoriedade de trabalhar a temática da História e Cultura Afro-Brasileira, também, a partir dela, o ensino de História e Cultura Indígena. 
No tocante ao ensino de História e cultura indígena nas redes de educação básica, além das práticas docentes, as leis e diretrizes deveriam reverberar também em toda a produção didática e paradidática produzida a partir delas. Deste modo, pelo menos sob o ponto de vista da legislação educacional, não incluir ou subdimensionar a história indígena nos conteúdos de história do Brasil poderia ser compreensível (embora não justificável), até 2008, em virtude de todo um processo histórico colonização e colonialidade que imperou também na produção dos livros didáticos. Todavia, a mesma postura, a partir de então, incorre no descumprimento de um decreto-lei de âmbito federal e uma desvalorização completa dos esforços políticos, acadêmicos e institucionais que vêm sendo feitos por meio de diversas pesquisas realizadas sobre a temática da diversidade étnico-racial e sua inclusão da produção didática brasileira a partir desta data.

Visando contribuir com o esforço analítico-crítico dos muitos pesquisadores e pesquisadoras que se debruçam sobre a temática do ensino de História Indígena, o presente artigo visa expor alguns resultados obtidos através de um projeto de pesquisa desenvolvido junto ao Departamento de Metodologia de Ensino da Universidade Federal de Santa Catarina (MEN-UFSC), intitulado "A Lei n. 11645/08 e o Ensino de História e Cultura Indígena na rede pública municipal de Florianópolis a partir do material didático de História recomendado pelo PNLD". O projeto foi concebido para analisar conteúdos e possibilidades de utilização dos materiais didáticos de História referendados pelo Programa Nacional do Livro e do Material Didático (PNLD) e distribuídos à rede municipal de educação de Florianópolis/SC. visar

Propondo refletir sobre a forma com que a temática da história e cultura indígena vem sendo abordada pelos materiais didáticos distribuídos às escolas, especialmente a partir da promulgação da Lei n. 11645/08, buscou-se, primeiramente, identificar se as abordagens presentes em uma das coletâneas didáticas distribuídas em grande parte das escolas da rede municipal educação de Florianópolis ${ }^{3}$ contribuem para promoção de aprendizagens consistentes sobre

3 O município de Florianópolis possui um total de 36 escolas de educação básica, que atendem cerca de 17000 estudantes do 1으 ao 9a ano do Ensino Fundamental (FLORIANÓPOLIS, 2015, p. 7). Destas 36 escolas, 11 atendem estudantes do 1 으 ao 5o ano e 25 atendem estudantes de todas as séries do Ensino Fundamental. No projeto desenvolvido, analisamos os livros didáticos 
interculturalidade e para o rompimento com visões estereotipadas e preconceituosas sobre a história e a cultura das populações indígenas. Junto a isso, pretende-se colaborar com indicações que poderiam orientar as escolas e professores a selecionarem aqueles materiais que proporcionem maiores contribuições nos campos indicados. A coletânea analisada, Vontade de Saber: História, será devidamente apresentada mais adiante neste artigo.

O propósito epistemológico deste artigo ganha relevância quando se observa que o próprio Guia PNLD História 2017 reconhece que a temática indígena ainda é "[...] o componente mais frágil no conjunto das obras didáticas aprovadas no PNLD, sendo o aspecto que merece maior grau de investimento por parte de autores, de editoras e de professores no uso das coleções" (BRASIL, 2016, p. 33). Além disso, a aprovação das Diretrizes Operacionais para a implementação da história e das culturas dos povos indígenas na Educação Básica, em decorrência da Lei n. 11.645/20084, prevê ações no sentido de colaborar e construir políticas públicas e processos pedagógicos que reforcem a implementação da referida lei. Entre várias ações estruturantes constantes nas diretrizes operacionais, destacam-se as orientações sobre a produção e distribuição de material didático sobre o tema:

[...] o MEC orienta para que os livros didáticos não veiculem preconceitos, estereótipos ou qualquer outra forma de discriminação; que abordem temas relacionados às questões da identidade e das diferenças, bem como reconheçam a contemporaneidade dos povos indígenas, tornando esses livros ferramentas importantes na formação contínua dos professores, desenvolvendo também nos estudantes uma consciência reflexiva crítica a respeito de sua própria sociedade e história, bem como dos grupos que as constituem. (BRASIL, 2015, p. 5).

Partimos da hipótese de que a partir da promulgação da Lei n. 11645/08 houve uma ampliação na quantidade e na qualidade dos livros didáticos sobre história e cultura indígena no Brasil, fornecidos às redes públicas de educação básica. Assim sendo, buscou-se identificar se os conteúdos sobre história e cultura

de História do chamado Ensino Fundamental II, isto é, o nível que abrange do 6o ao 9o ano.

4 Estas diretrizes são homologadas pela Câmara da Educação Básica (CEB) do Conselho Nacional de Educação (CNE), por meio do Parecer CNE/CEB n. 14/2015, de 11 de novembro de 2015, e publicadas no Diário Oficial da União, em 18 de abril de 2016. 
indígena, presentes nos exemplares analisados, contribuem efetivamente para a problematização de (pré) conceitos, para questionar as danosas generalizações e estabelecer reflexões sobre interculturalidade e diversidade no ambiente escolar e/ou fora dele.

Na presente análise, optou-se por não focalizar a utilização do livro didático por parte dos professores e professoras, pois compreende-se que as formas com que os(as) mesmos(as) escolhem e selecionam os conteúdos não são análogas, assim como não é a recepção das informações por parte dos(as) estudantes. Ao mesmo tempo, como o próprio guia do livro didático do Ministério da Educação (MEC) refere-se ao mesmo como um suporte ou um instrumento de apoio às aulas, optou-se por concentrar a análise nas suas possibilidades ou impossibilidades pedagógicas no tocante ao ensino de história indígena.

\section{LIVROS DIDÁTICOS, RELAÇÕES ÉTNICO-RACIAIS E ENSINO DE HISTÓRIA INDÍGENA}

Embora nos últimos anos o PNLD tenha ampliado a concepção de "material didático", admitindo a inclusão de ferramentas diversificadas de apoio à prática educativa (entre as quais softwares e jogos educacionais, materiais de reforço e correção de fluxo, materiais de formação, materiais destinados à gestão escolar, entre outros), o livro didático, por sua capacidade de sintetizar e organizar conteúdos, continua sendo o principal instrumento pedagógico utilizado pelos professores da educação básica. O livro didático de História ainda se constitui como uma importante ferramenta para auxiliar na difusão e discussão dos conteúdos históricos, por conta de sua objetividade, qualidade imagética e capacidade de sintetizar abordagens teóricas de difícil assimilação para estudantes da Educação Básica.

Ocorre, porém, que este instrumento, algumas vezes, acaba sendo utilizado enciclopedicamente, contribuindo de forma perigosa para o estabelecimento de verdades históricas, visões unilaterais e leituras fragmentadas e simplificadas da história. Não é raro encontrar professores que, pressionados por gestores, coordenadores pedagógicos e mesmo pais, sentem-se forçados a seguir o livro didático como um manual, cujo conteúdo será implacavelmente cobrado em exames, vestibulares, concursos, etc. Neste contexto, quaisquer outras discussões, 
por mais importantes que sejam, são tomadas como "atraso da matéria" (PINSKY; PINSKY, 2018, p. 29). ${ }^{5}$

Pode-se observar, todavia, que desde 1985, quando foi instituído o embrião do PNLD, muitos avanços e aperfeiçoamentos foram alcançados no tocante à seleção dos livros didáticos destinados às escolas brasileiras. Atualmente, rigorosas e detalhadas exigências são estabelecidas pelos avaliadores para a aprovação de uma obra. No caso do componente curricular história, além de uma complexa revisão para evitar erros conceituais, anacronismos e simplificações excessivas, é cada vez mais comum a existência de cobranças relativas à representação de fontes primárias, indicação de bibliografias complementares, trechos de obras historiográficas, lista de filmes históricos, abordagens interdisciplinares, entre outras estratégias.

De modo geral, como identifica Flávia Caimi (2017), "O modelo clássico de livro didático, em que o texto ocupava o lugar central pouco a pouco vem cedendo lugar para um estilo mais polifônico, com um conjunto de elementos que enriquecem a narrativa histórica principal" (CAIMI, 2017, p. 41). Ainda assim, não se pode esquecer que, como o próprio adjetivo explicita, o livro didático precisa passar por um processo de simplificação do conhecimento histórico para transformá-lo em conhecimento histórico escolar (FONSECA, 2012, p. 97). Este processo de simplificação faz-se necessário para auxiliar no processo de ensino aprendizagem, promovendo uma adaptação de acordo com o nível/série, além de orientar uma sequência lógica do conteúdo. Se por um lado esta simplificação possui uma função didática importante para a educação básica, por outro, incorre-se no risco de extrapolar nas sínteses e nos esquemas, comprometendo o senso crítico e reflexivo que a aula de História deveria promover. Selva Fonseca (2012) destaca que:

5 É importante destacar, contudo, que naqueles contextos sociais e escolares onde o papel do professor compreende noções e ações mais amplas, onde se incluem reflexões e críticas aos conteúdos e valores associados aos mesmos, o papel do livro didático tende a ter seu protagonismo reduzido em relação às distintas formas de organização didático-pedagógica do docente. Nestes casos, as fontes utilizadas para as aulas tendem a ser diversas e relacionadas às realidades dos estudantes ou de acordo com a perspectiva dos temas transversais. Tal perspectiva possibilita um maior protagonismo dos professores para organizarem suas metodologias, permitindo uma abrangência que, na maioria das vezes, está fora do alcance dos livros didáticos disponíveis. 0 contraponto desta autonomia, porém, está na ampliação da carga de trabalho dos professores, que na maioria dos casos, não tem estes "extras" computados em sua carga horária de docência. 
O processo de transposição e simplificação no âmbito da difusão implica tornar definitivas, institucionalizadas e legitimadas pela sociedade determinadas visões e explicações históricas. Essas representações transmitidas simplificadamente trazem consigo a marca da exclusão. O processo de exclusão inicia-se no social, em que "alguns atos" são escolhidos e "outros" não, de acordo com critérios políticos. (FONSECA, 2012, p. 97).

Direcionando a reflexão de Fonseca (2012) para o campo do ensino de História no contexto das relações étnico-raciais, é possível inferir que muitas das representações presentes nos livros didáticos, mesmo que sem intencionalidade clara, contribuem para a exclusão de determinados sujeitos históricos em detrimento de outros. Não é novidade afirmar que, durante muito tempo, a perspectiva eurocêntrica de ensino da história brasileira, inaugurada por Francisco Adolfo de Varnhagen em sua História Geral do Brasil, de 1854, promoveu o enaltecimento dos colonizadores europeus em detrimento aos africanos escravizados, afro-brasileiros e indígenas. Embora esta abordagem, originada em meados do século XIX, tenha sido vista e revista ao longo dos últimos 150 anos, sua essência acabou trazendo consequências lastimáveis para a história destas populações, cujos reflexos são presentes até os dias atuais.

Durante os tempos em que vigoraram algumas políticas progressistas no campo da educação básica, (entre meados dos anos 1990 até 2015, mais especificamente), foram instituídos instrumentos jurídicos de grande importância para a valorização e reconhecimento das diferenças, conforme já descrito anteriormente. $\mathrm{O}$ intuito primeiro destes instrumentos foi contribuir para o rompimento de narrativas preconceituosas e, na sua esteira, reforçar e valorizar as diferenças. Iniciativas exemplares neste sentido, as promulgações das Leis n. 10639/03 e 11645/08, contribuíram de maneira mais pontual para a educação no contexto das relações étnico-raciais:

A proposição de Leis, como a 10.639 e a 11.645, é um exemplo significativo dessa realidade mutável. Surgido como oriundo da força de movimentos sociais amparados num debate do direito à memória e ao passado, o tratamento escolar das temáticas afro-brasileira e indígena insere-se num debate mais amplo, em torno da afirmação de direitos sociais, do reconhecimento de identidades silenciadas e homogeneizadas pela própria historiografia e da busca por uma Educação mais ampla para as relações étnico-raciais. (BRASIL, 2016, p. 16). 
Ensino história indígena em livros didáticos: problematizações a partir de uma coletânea distribuída na rede municipal de ensino de Florianópolis, SC

É importante ressaltar, como destaca o trecho do PNLD, que nenhuma das leis citadas foi produto exclusivo de uma observância do Estado brasileiro sobre a sua necessidade urgente. Elas são, sobretudo, o resultado marcante de demandas levantadas pelos respectivos movimentos negro e indígena, os quais trazem na sua própria trajetória as marcas da discriminação e do preconceito. Não se trata, no entanto, como ressaltam Mauro Cezar Coelho e Wilma Baía Coelho (2015), de negar o papel dos espaços acadêmicos e institucionais na discussão e conformação de normativas legais para a implementação das leis de inclusão, mas de reconhecer a sua condição de coadjuvante (COELHO; COELHO, 2015, p. 285). É preciso evidenciar, desse modo, a existência de um esforço conjunto entre os meios acadêmicos, militância social e instâncias políticas, para a elaboração de projetos dos quais se originaram os presentes instrumentos legais, que lançam luz a uma história de sujeitos e territórios deixados nas sombras do ensino de história durante algumas gerações.

Assumindo que a escola tem uma função basilar na constituição das identidades dos sujeitos e na conformação de uma consciência histórica, tanto as representações construídas pelos docentes acerca dos conteúdos ministrados, quanto as ferramentas didáticas por eles utilizadas, precisam ser sopesadas quando se almeja uma educação para a diversidade. O PNLD, nos últimos anos, reforçou as exigências aos autores de livros didáticos de história no que diz respeito ao tratamento das questões étnico-raciais. Questões como o protagonismo dos diferentes sujeitos ao longo dos tempos, pertencimentos identitários e lutas sociais por direitos, tiveram especial atenção dos avaliadores. No que tange à temática indígena, opera-se para que a mesma "[...] seja foco reflexivo e problematizador para sujeitos indígenas e não indígenas no tempo presente" (BRASIL, 2016, p. 34).

Ao longo das últimas décadas, tanto a historiografia quanto o campo do ensino de História vêm reforçando a ideia de que o ensino da disciplina precisa possibilitar a apropriação de conhecimentos plurais, que valorizem a diversidade e as especificidades culturais dos diferentes povos, contribuindo para a constituição de uma sociedade mais justa e igualitária (MONTEIRO, 2001; ALMEIDA, 2010; 2017; COELHO \& COELHO, 2015; BITTENCOURT, 2018). A legislação educacional, de modo geral, vem reforçando este caráter a partir de leis específicas, como as citadas aqui. Neste sentido, as Diretrizes Operacionais para a implementação da história e das culturas dos povos indígenas na Educação Básica, homologadas em 
2015 e lançadas no ano de 2016, são de suma importância, tendo em vista que reforçam, além dos conteúdos, saberes e competências, também as atitudes e valores que permitem aos estudantes reconhecerem a sociedade brasileira como pluriétnica e pluricultural (BRASIL, 2015, p. 10). No intuito de promover um salto qualitativo no ensino de história indígena, 8 orientações principais são destacadas nas diretrizes como imprescindíveis no trabalho escolar:

1. Reconhecer que os povos indígenas no Brasil são muitos e variados, possuem organizações sociais próprias, falam diversas línguas, têm diferentes cosmologias e visões de mundo, bem como modos de fazer, de pensar e de representar diferenciados. 2. Reconhecer que os povos indígenas têm direitos originários sobre suas terras, porque estavam aqui antes mesmo da constituição do Estado brasileiro e que desenvolvem uma relação coletiva com seus territórios e os recursos neles existentes. 3. Reconhecer as principais características desses povos de modo positivo, focando na oralidade, divisão sexual do trabalho, subsistência, relações com a natureza, contextualizando especificidades culturais, ao invés do clássico modelo de pensar esses povos sempre pela negativa de traços culturais. 4. Reconhecer a contribuição indígena para a história, cultura, onomástica, objetos, literatura, artes, culinária brasileira, permitindo a compreensão do quanto a cultura brasileira deve aos povos originários e o quanto eles estão presentes no modo de vida dos brasileiros. 5. Reconhecer que os índios têm direito a manterem suas línguas, culturas, modos de ser e visões de mundo, de acordo com o disposto na Constituição Federal de 1988 e que cabe ao Estado brasileiro, protegê-los e respeitá-los. 6. Reconhecer a mudança de paradigma com a Constituição de 1988, que estabeleceu o respeito à diferença cultural porque compreendeu o país como pluriétnico, composto por diferentes tradições e origens. 7. Reconhecer o caráter dinâmico dos processos culturais e históricos que respondem pelas transformações por que passam os povos indígenas em contato com segmentos da sociedade nacional. 8. Reconhecer que os índios não estão se extinguindo, têm futuro como cidadãos deste país e que, portanto, precisam ser respeitados e terem o direito de continuarem sendo povos com tradições próprias. (BRASIL, 2015, p. 10).

Como se percebe, as diretrizes contemplam questões fundamentais para o ensino de História Indígena. Pela dificuldade de sintetizar as informações de todos os pontos em um artigo, optou-se por aprofundar a análise da coletânea didática de História a partir de três questões principais, que, por sua abrangência, contemplam direta ou indiretamente todos os pontos ressaltados nas diretrizes. São eles: Diversidade cultural (relacionando os conteúdos referentes às cosmologias, 
línguas e organização social das populações indígenas); Direitos (analisando a menção ou não a questões relacionadas à saúde, educação e dinâmica territorial e cultural) e Representações socioculturais (observando se existe uma ampliação do leque tradicional centralizado na cultura material, religião e alimentação, para outros campos, como literatura, política, entre outras).

\section{ENSINO DE HISTÓRIA INDÍGENA NA REDE MUNICIPAL DE ENSINO DE FLORIANÓPOLIS - A COLETÂNEA VONTADE DE SABER: HISTÓRIA}

Em consulta ao Departamento de Bibliotecas Escolares (DEBEC) da Secretaria Municipal de Educação de Florianópolis, setor responsável pelo armazenamento e distribuição de materiais didáticos às escolas do município, verificou-se que, no ano de 2017, 4 coletâneas de livros didáticos do complemento curricular História do 60 ao 9a ano foram enviadas às escolas da rede municipal. Estes materiais foram distribuídos pela secretaria de educação às 25 unidades educativas do município, cujos currículos integram os anos finais do Ensino Fundamental. As coletâneas são as seguintes: Projeto Teláris História, da Editora Ática, presente em 1 escola; História: sociedade e cidadania, da Editora FTD, presente em 5 escolas; Projeto Araribá História, da Editora Moderna, presente em 1 escola e Vontade de Saber: História, também da Editora FTD, presente em 18 escolas.

Pela necessidade de sintetizar as informações para um artigo, optou-se por focar a análise em somente uma das obras citadas. Desse modo, pela presença no maior número de escolas, o que se configura, em tese, em um número muito maior de estudantes que acessam seus conteúdos, a escolha recaiu sobre a coletânea Vontade de Saber: História, de autoria de Marcos César Pellegrini, Adriana Machado Dias e Keila Grinberg (2012a; 2012b; 2012c; 2015a; 2015b; 2015c). A análise foi dimensionada nos exemplares referentes aos PNLDs 2014/2016 e 2017/20196. Destes, foram focalizados os livros referentes aos 7으, 8ㅇ e 9o anos, pois são aqueles que trazem em seus conteúdos programáticos, componentes

\footnotetext{
6 Esta escolha se justifica por se tratarem das duas últimas coletâneas aprovadas pelo PNLD e sugeridas às redes de educação básica durante o período de vigência da pesquisa (2018/2019). No caso da coletânea referente ao PNLD 2017/2019, a análise foi feita a partir de exemplares de "manuais do professor". Seguindo uma lógica metodológica, optou-se por não considerar as "orientações ao professor" presentes nesta coletânea, mantendo a análise idêntica à efetuada na coletânea 2014/2016, ou seja, apenas em seu conteúdo primário.
} 
sobre História do Brasil, referentes aos períodos pré-colonial, colonial, imperial e republicano.

Figura 1 - Coletânea Vontade de Saber: História (PNLDs 2014/2016 e 2017/2019)

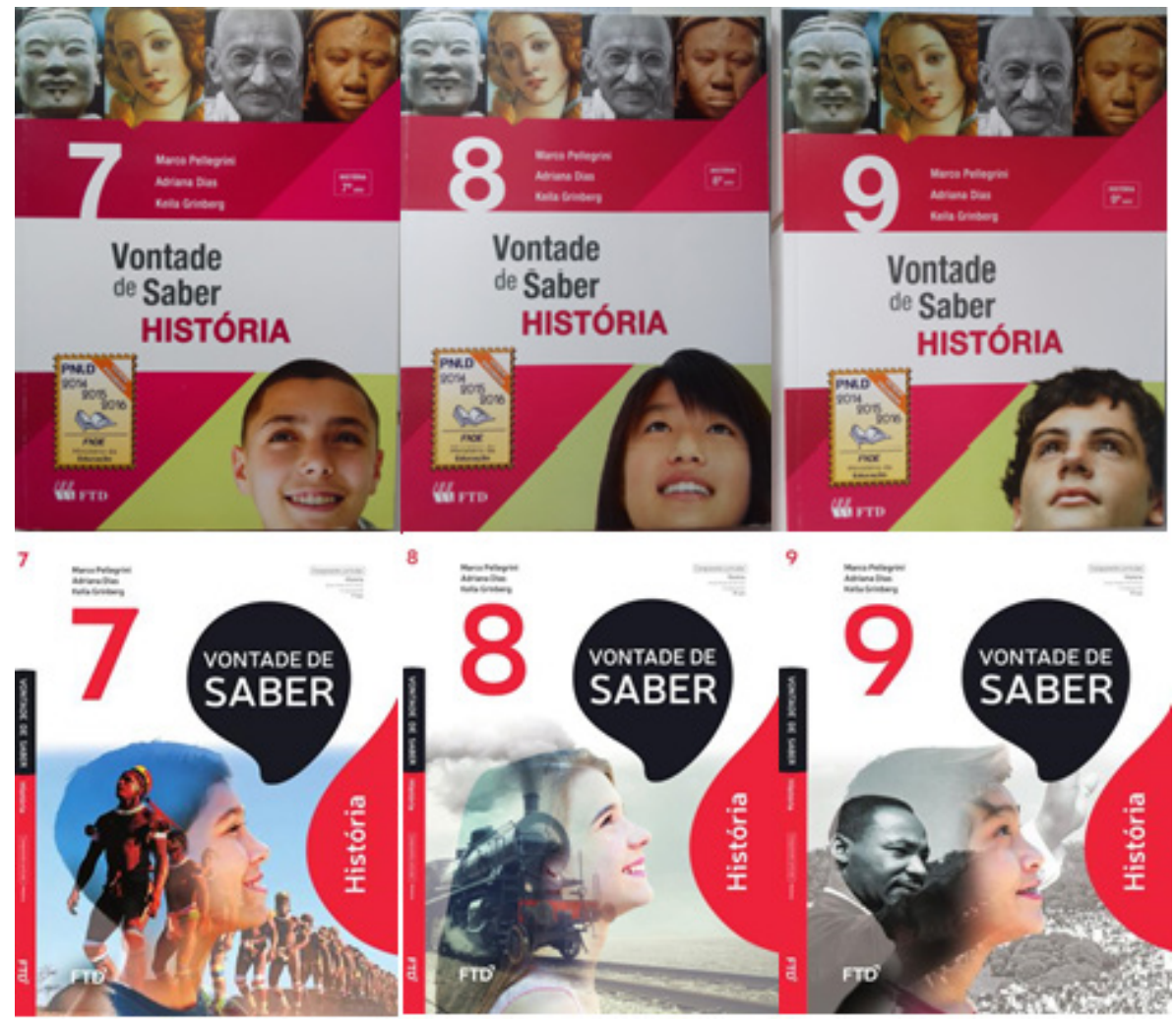

Fonte: Acervo do autor.

No guia de livros didáticos do PNLD 2017/2019, pode-se observar que a coletânea Vontade de Saber: História recebe elogios dos avaliadores por apresentar estratégias e recursos importantes, tais como mapas detalhados, sugestão de atividades, por trabalhar a interdisciplinaridade e a transdisciplinaridade, além de proporcionar informações adicionais para o trabalho com a internet, a televisão, o cinema, as artes gráficas e a literatura (BRASIL, 2016, p. 53). No mesmo guia há ainda o reconhecimento de que a coleção contribui para a promoção da educação para as relações étnico-raciais, especialmente porque traz maior quantidade de conteúdos 
ligados à História da África e dos afro-brasileiros, em todos os seus volumes (BRASIL, 2016, p. 55). No tocante à temática indígena, todavia, observa-se que a quantidade de conteúdos e abordagens é significativamente menor. O próprio guia reconhece que há carência de orientações teórico-metodológicas quanto à abordagem da temática indígena. Por isso, sugere que o professor busque auxílio de outras fontes para aprofundar o trabalho sobre os povos indígenas no Brasil (BRASIL, 2016, p. 55-6).

De posse dessa informação, julga-se importante, então, apontar qual o papel atribuído aos indígenas nos exemplares dos três níveis da coletânea. O intuito, neste momento, não é apenas avaliar a forma como são abordados os conteúdos referentes à temática, identificando suas falhas e carências. A intenção é, principalmente, apresentar proposições sobre como os conteúdos relativos à história e cultura indígena poderiam estar sendo abordados nos diferentes contextos históricos apresentados por esta e por outras coletâneas didáticas de História, o que contribuiria para a sua conformação à Lei n. 11645/08 e suas diretrizes. Assim sendo, optou-se por efetuar a análise individual dos volumes, apresentar seus conteúdos e discorrer sobre as suas potências, carências e possibilidades de complementação das informações.

\section{Vontade de Saber: História - 7o ano}

O conteúdo do volume do 70 ano aborda um período bastante longo da história, cobrindo desde a formação da Europa Medieval, no século V, até a consolidação da colonização na América Portuguesa, no século XVIII. Nesta conjuntura, a presença indígena no território brasileiro é exposta na versão PNLD 2014/2016 como apêndice de um capítulo em que o(as) autor(as) se propõem a estudar o continente americano em período anterior à presença europeia. Neste capítulo, intitulado "A América antes da chegada dos europeus", a diversidade de povos existentes no continente é apresentada por meio de um mapa etnohistórico retirado do livro A América que os europeus encontraram, escrito por Henrique Peregalli (1994). Junto a este mapa, estão situadas algumas ilustrações que apresentam imagens de indígenas de diferentes povos, entre os quais Esquimós, Maias, Incas, Sioux, Guaranis e Apiacás.

Embora não exista uma indicação sobre a autoria das imagens, nem uma explicação sobre os objetivos destas representações, sua presença no livro é importante, 
pois atenta, mesmo que minimamente, para a compreensão da existência de uma diversidade cultural e uma multiplicidade de povos vivendo no continente em período anterior à invasão europeia. No decorrer do capítulo, observa-se a manutenção da abordagem tradicional clássica presente na grande maioria dos livros didáticos de História; isto é, mantém a ênfase analítica nas civilizações mesoamericanas e andina (maias, astecas e incas), em detrimento a outras populações originárias do continente em diferentes épocas e contextos. A ênfase a estas populações ocorre já no título do subcapítulo, denominado "Algumas civilizações importantes da América" (PELLEGRINNI; DIAS; GRINBERG, 2012a, p. 79).

É importante esclarecer que ao enfatizar este detalhe, não se pretende questionar ou subvalorizar a importância destas populações para história do continente. Ressalta-se, simplesmente, que a abordagem presente no capítulo coloca em evidência uma relação dicotômica quando atribui maior destaque a populações cujas configurações socioculturais, dinâmicas político-religiosas, modos de produção, redes de relacionamento, entre outras características, acabaram tornando-as mais (re)conhecidas ao redor do mundo. Neste modelo, atribui-se às mesmas denominações do tipo sociedades complexas ou altas culturas, " [...] que desenvolveram elementos característicos de uma civilização" (PELLEGRINNI; DIAS; GRINBERG, 2012a, p. 79), galgando, por isso, mais destaque do que os povos das chamadas sociedades simples ou frias $^{7}$, termo geralmente associado aos povos com características nômades e seminômades que, em virtude das particularidades sociais, territoriais e culturais, não desenvolveram padrões organizacionais e tecnológicos similares aos incas, maias e astecas.

No mesmo capítulo do livro do 70 ano, há uma fotografia de um pai e um filho da etnia Waurá, povo habitante do Parque Indígena no Xingu (MT). Na legenda da

\footnotetext{
7 Expressão cunhada pelo antropólogo Claude Levy Strauss e erroneamente interpretada como "sociedades sem história". Maria Amélia Schmidt Dickie explica que, embora leituras equivocadas tenham disseminado a percepção de que ao denominar certas sociedades indígenas de sociedades frias, o antropólogo francês estivesse considerando que estas não possuíam história, o que Lévi-Strauss alertava é que estas sociedades não concebem a mudança relacionada ao tempo. A estrutura social das chamadas sociedades quentes contém em si os mecanismos de mudança, concebida como produtora da ordem e não como desagregadora. Neste caso, o tempo é concebido como instrumento - como algo manipulável - de transformação e estas são as sociedades que tem história porque fazem uma relação entre tempo e mudança (DICKIE, 2012, p. 10).
} 
foto consta a seguinte descrição: "Fotografia recente de pai e filho indígenas da etnia Waurá". Chama a atenção, neste caso, o fato de os dois estarem representados com pinturas e adornos corporais característicos dos momentos de festas e/ou rituais. Tal fato não causa estranhamento quando se explicita o contexto e o objetivo para o qual a fotografia foi tirada. Porém, como não é o que acontece no caso, a falta de contextualização da fotografia Ihe confere fragilidade enquanto representação histórica, principalmente porque tende à manutenção de uma concepção naturalizada da cultura indígena (OLIVEIRA, 1999, p. 115). Onde está o perigo destas representações descontextualizadas? O etnólogo João Pacheco de Oliveira (1999) explica com mais propriedade:

A concepção naturalizada de cultura adequa-se perfeitamente à representação do senso comum sobre os índios, formando um complexo ideológico de difícil desmontagem. A representação cotidiana sobre o índios, como já dissemos em outras ocasiões, é a de um indivíduo morador da selva, detentor de tecnologias mais rudimentares e de instituições mais primitivas, pouco distanciado portanto da natureza.[...] Tal representação traz imbricada consigo a suposição de primitividade, que a qualquer momento pode gerar a possibilidade de vir a instituir-se uma polaridade entre as culturas indígenas (quase) intocadas (seriam as autênticas) e aquelas afetadas por processos de aculturação (seriam inautênticas pois conteriam elementos exógenos e espúrios). (OLIVEIRA, 1999, p. 115).

O risco da exposição de uma concepção naturalizada de cultura é a manutenção de (pré)conceitos a respeito das sociedades indígenas no tempo presente. O "chão da escola", neste contexto, surge como espaço de reprodução ou ruptura dos estereótipos arquetípicos construídos sobre os povos originários. Assim sendo, o cuidado, a sensibilidade da representação, precisa avançar não apenas na prática docente, mas também nos instrumentos didáticos que, em grande medida, a consubstanciam.

Ao ressaltar a questão da falta de contextualização neste caso, não se quer afirmar que o(as) autor(as) da coletânea compartilhem da suposição de primitividade ou de cristalização sociocultural das populações indígenas, até porque, em alguns trechos do livro o(as) mesmo(as) tem o cuidado de explorar a temática indígena fazendo uma relação conceitual entre passado e presente. Exemplo disso é que, ao explicar a situação dos indígenas no Brasil atual, abordam a problemática da invasão de territórios indígenas e a desestruturação de muitas 
comunidades devido ao contato. A ilustração do cotidiano de uma comunidade indígena na atualidade é apresentada em página inteira com a representação gráfica uma aldeia Caiapó. Essa ilustração é importante, pois demonstra algumas permanências em termos de referências tradicionais da cultura (moradias, artes, organização sociopolítica) mas também as apropriações feitas a partir do contato (casas de alvenaria, televisão, futebol, entre outras) (PELLEGRINNI; DIAS; GRINBERG, 2012a, p. 88-9).

A maior crítica a ser feita neste caso é com relação ao tímido esforço analítico a respeito da imagem por parte do(as) autor(as). Embora a imagem seja referenciada como uma representação artística feita com base em estudos históricos (PELLEGRINNI; DIAS; GRINBERG, 2012a, p. 89), estas fontes não se somam à leitura interpretativa da imagem. Não se evidencia uma problematização a respeito das apropriações e ressignificações de elementos não indígenas por parte das populações indígenas e, ao mesmo tempo, não apresenta o processo inverso, isto é, as heranças indígenas presentes em nosso cotidiano, seja na língua, na alimentação, na religiosidade, entendidas como heranças base, mas também outras que vem sendo mais evidenciadas na atualidade, como as iniciativas de produção de alimentos com base em saberes indígenas, as manifestações na literatura, a onomástica, entre outras. Essa forma estendida de compreensão das partilhas de influências auxiliaria os estudantes a compreenderem a concepção de dinamicidade da cultura, conforme apontado linhas atrás.

No capítulo dedicado à colonização na América Portuguesa há uma importante associação de imagens. Num pormenor é apresentada a ilustração corriqueira de um mapa da costa brasileira, com figuras de indígenas cortando e transportando pau-brasil, (recorrente em praticamente 100\% dos livros didáticos sobre o período colonial brasileiro). Em outro, há uma fotografia do ano 2000, sobre os protestos de diferentes povos indígenas frente ao evento de comemoração aos 500 anos de "descobrimento" (PELLEGRINNI; DIAS; GRINBERG, 2012a, p. 178-9). Considero esta associação importantíssima, pois destaca um dos aspectos que a "Nova História Indígena" vem tentando construir desde a década de 1990: o protagonismo indígena. ${ }^{8}$ Ao contestar a comemoração de 500 anos de exploração

8 Neste período inauguraram-se ainda debates e reflexões a respeito da história indígena ensinada nas escolas e da presença indígena em livros didáticos. Sobre este último ponto, vale destacar 
do território, que representou violência, desestruturação e desaparecimento de diversas etnias, temos uma demonstração de agência por parte das inúmeras etnias indígenas existentes no país. Através de seu engajamento em pautas sociais, culturais e políticas, deixam claro que a história dos indígenas no Brasil precisa ser conectada, articulada com a história nacional e não submissa à mesma, como as narrativas simplificadoras buscaram fazer ao longo dos séculos XIX e XX. Este é um direito constitucional e está previsto nas diretrizes para o ensino de História e Cultura Indígena.

O mesmo livro do 70 ano, na versão PNLD 2017/2019, traz na capa uma montagem fotográfica onde aparece um grupo de indígenas em uma fila, ornamentados com pinturas e adereços, indicando a prática de algum ritual, sobreposta pela foto de um menino sorridente. A autoria é indicada na contracapa, "Fotomontagem de José Victor E. C. formada pelas imagens Renato Soares/Pulsar (fundo) e José Vitor Alorza/ASC images (perfil)" (PELLEGRINNI; DIAS; GRINBERG, 2015a, contracapa). Não existe nenhum tipo de explicação sobre o contexto da imagem e muito menos a que povo e época pertencem estes indígenas.

Em relação ao conteúdo, apresenta o mesmo mapa da versão anterior (PEREGALLI, 1994), assim como as mesmas imagens para representar a diversidade dos povos indígenas da América. Mantém ainda a mesma ênfase nas características, sociais, econômicas e culturais de Incas, Maias e Astecas em detrimento às demais populações originárias do continente americano. Esta versão não apresenta a imagem do pai e filho da etnia Waurá como vetor da diversidade dos índios no Brasil. Em vez dela, a imagem apresentada é um desenho do artista francês Hercule Florence (séc. XIX), representando alguns indígenas do povo Apiacá, que habitou a região onde hoje se encontra o estado do Mato Grosso. Esta substituição é combinada com a exclusão da fotografia do ano 2000,

o revelador artigo Livros didáticos e fontes de informações sobre as sociedades indígenas no Brasil, de Luiz Donizete Benzi Grupioni, publicado no livro organizado pelo próprio Grupioni em parceria com Aracy Lopes da Silva (1995), intitulado: "Temática Indígena na Escola: novos

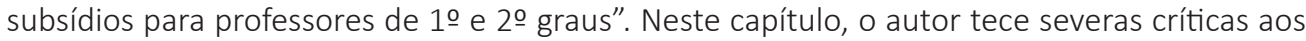
livros didáticos produzidos no Brasil à época da publicação do artigo (1995), considerando que os mesmos, embora se esforçassem a disseminar uma cultura de respeito e tolerância aos grupos etnicamente diversos, mantinham a cultura indígena presa a um passado estanque, aparecendo somente em função do colonizador, em situação de coadjuvância, tendo subtraída sua condição de sujeito histórico (GRUPIONI, 1995, p. 487). 
que trazia os protestos de indígenas ao evento de comemoração aos 500 anos de "descobrimento".

No computo geral, é possível considerar que o volume representa um recuo no tocante ao esforço de aproximar os vínculos de um passado colonial com a atual conjuntura. Deste modo, o conteúdo apresentado reforça a cristalização dos indígenas em um passado remoto, não datado e não contextualizado, pois, ao negligenciar as trajetórias históricas dos povos originários, o seu engajamento político, suas lutas por demandas sociais e territoriais, destitui destes a capacidade de atuação como sujeitos históricos plenos, cujas escolhas, demandas, alianças e negociações, influenciaram sobremaneira o avanço ou o retrocesso do processo de colonização.

O maior problema identificado no livro do 7ํ ano, nas duas versões, é a sua falta de consistência argumentativa. Se em certos trechos dedicados à colonização europeia há um destaque para a presença e para o protagonismo indígena neste período, em outros persiste uma versão da história onde o papel das populações indígenas é relegado a um apêndice em relação aos colonizadores. Tal contradição se deve à abordagem escolhida para identificar as relações estabelecidas entre indígenas e não indígenas, ainda baseadas em exploração da mão de obra, escravização, catequização e resistências, onde nenhum dos temas é explorado de forma mais detalhada e com exemplificações que permitam evidenciar as ações e as escolhas indígenas. Neste sentido, embora haja um esforço para identificar a diversidade cultural durante o período, as dinâmicas socioculturais representativas das relações de alianças, negociações e dinâmicas próprias de cada povo não são trazidas no texto, o que prejudica a atribuição de protagonismo aos indígenas, como propõem as diretrizes para a aplicação da Lei n. 11.645/08.

Vontade de Saber: História - 8o ano

O livro do 8 ano desta coletânea abarca o período histórico que vai da chegada da família real portuguesa ao Brasil em 1808, até o fim do período monárquico, em 1889. O enfoque temático do livro está orientado para as questões políticas e econômicas do Brasil Império, com pouquíssimo espaço para o tratamento da diversidade étnico-racial do país naquele contexto. No período de 81 anos, a presença indígena é praticamente ignorada, sendo que em poucos momentos se faz referência aos mesmos. 
Um destes momentos é logo no capítulo 1, de introdução ao estudo da História, onde se solicita a análise de uma charge do cartunista Angeli (publicada em fevereiro de 2005 na Folha de São Paulo) onde estão dispostas duas imagens em paralelo, representando um indígena em situações distintas no passado e no presente (uma em um ambiente de floresta e outra em um lixão). Atual e importantíssimo, o tema que retrata a disputa ideológica pela demarcação de terras indígenas por setores favoráveis e contrários não é explorado. Há necessidade de maior aprofundamento e discussões embasadas para não deixar a discussão fluir apenas para a perspectiva exclusiva da análise de fontes históricas.

Os outros dois momentos se referem a um pequeno trecho do subcapítulo referente à sociedade brasileira pós-independência, onde se destaca que existiriam cerca de 800 mil indígenas à época (PELLEGRINNI; DIAS; GRINBERG, 2012b, p. 156) e, num quadro chamado "Explorando o tema", no qual o(as) autor(as), discorrem sobre a formação da identidade nacional a partir da observação do famoso pano de boca desenhado por Jean Baptiste Debret em 1822, com o objetivo de homenagear o recém criado Império (PELLEGRINNI; DIAS; GRINBERG, 2012a, p. 188). Em nenhuma destas oportunidades há uma problematização dos temas.

A versão do livro para o PNLD 2017/2019 também não avança em nada em relação à temática, mantendo as mesmas únicas referências aos indígenas no Brasil que a versão anterior, embora apresente potencial para isso, como por exemplo, num mapa bastante interessante da província de São Paulo em 1886, organizado pela Sociedade Promotora de Imigração, onde aponta as "ótimas oportunidades" para os imigrantes que viessem para o Brasil em busca de terras e trabalho. No mapa, toda a região sudoeste paulista aparece em coloração verde, distinguindo-se do restante do mapa da província, onde podem ser lidos os seguintes dizeres: "terrenos despovoados" (PELLEGRINNI; DIAS; GRINBERG, 2015b, p. 259). Não há, porém, nenhum convite à reflexão e/ou problematização sobre as intencionalidades das companhias colonizadoras em apresentar estes territórios como despovoados. Referências aos povos da cultura Jê e Tupi-Guarani, cuja presença histórica na região remonta aos tempos pré-coloniais (BORELLI, 1984; MONTEIRO, 1994; RODRIGUES, 2001; SPOSITO, 2006) também não aparecem.

A ideia que o livro didático do 8 o ano passa, em ambas as versões, é que os indígenas "desapareceram" das relações sociais do país durante o Império. 
Fatos históricos importantes que envolvem estas populações são relegados ao esquecimento. Não são contempladas questões fundamentais, que influenciaram as dinâmicas das relações das populações indígenas com o Estado Nacional, como as Cartas Régias protocoladas por Dom João VI nas quais o mesmo autoriza as chamadas "guerras justas" contra os índios botocudos de Minas Gerais e de São Paulo, revogadas apenas em 1831. Não é citado o projeto de integração dos índios à sociedade nacional, organizado por José Bonifácio de Andrada e Silva e publicado no seu livro intitulado Apontamentos para a Civilização dos Índios Bravos do Império do Brasil, de 1823. Pontos importantes sobre os direitos indígenas (ou a retirada deles) aos territórios ocupados também são negligenciados ao não se fazer referência ao Regulamento das Missões de Catequese e Civilização dos Índios (Decreto n. 426, de 24 de julho de 1845), singular documento indigenista do Império que orienta ações administrativas para indígenas aldeados e estabelece normativas para a criação de novos aldeamentos.

Os inúmeros conflitos bélicos ocorridos no período imperial, a exemplo da Cabanagem, da Revolução Farroupilha e da Guerra do Paraguai, tiveram impacto direto e indireto nas vidas de muitos povos indígenas, assim como tiveram na vida dos africanos e afro-brasileiros escravizados. Se por um lado o livro tem o mérito de apontar, em alguns casos, as consequências das guerras e revoltas para estes últimos, a participação ou mesmo as consequências das guerras para os povos indígenas no Brasil é completamente ignorada.

Na coletânea, a Lei de Terras (Lei n. 601, de 18 de setembro de 1850), que regulamenta a aquisição de terras no Brasil, estabelecendo a compra como a única forma de acesso às mesmas (o que teve um impacto enorme sobre as populações indígenas, pois ignorou-se a posse destas sobre seus territórios, considerando-os como terras devolutas e distribuindo-as para a colonização), é resumida a uma normativa governamental cujo objetivo era demarcar as propriedades, separando as terras públicas das privadas. As consequências da lei para camponeses pobres, ex-escravos e, em especial às populações indígenas não são detalhadas ao longo dos capítulos. Caso o fossem, implicariam em importantes elos de ligação que permitiriam, por exemplo, discorrer com mais propriedade sobre as circunstâncias expostas na charge apresentada no capítulo 1, cujo conteúdo levaria necessariamente a um debate sobre os direitos indígenas aos seus territórios historicamente ocupados, atendendo, assim, um dos pontos das diretrizes de 2016. 
Ensino história indígena em livros didáticos: problematizações a partir de uma coletânea distribuída na rede municipal de ensino de Florianópolis, SC

Vontade de Saber: História. 9o ano

Dedicado à análise histórica do mundo contemporâneo, os volumes do 9으 ano trazem em seu conteúdo um modelo de história integrada, apontando as transformações mundiais entre o final do século XIX até a contemporaneidade. Com relação ao Brasil, o conteúdo cobre desde a proclamação da República, em 1889, até o mundo contemporâneo (na versão PNLD 2014/2016, vai até a eleição de Dilma Roussef à presidência em 2010 e o PNLD 2017/2019 até sua reeleição em 2014). ${ }^{9}$ Verifica-se, ao longo dos capítulos, a inclusão de conceitos importantes para a compreensão do período, como política, cultura, trabalho, economia, ideologia, capitalismo, socialismo e etnocentrismo. Observa-se, no entanto, que há pouco espaço para a questão da diversidade étnica brasileira em suas páginas.

Para o início do período republicano, a ênfase neste campo é centrada na imigração, com destaque para o papel dos imigrantes no campo, nas cidades e suas formas de organização (ligas e sindicatos, principalmente). No tocante à questão afro-brasileira, o livro explora parcialmente o cotidiano dos ex-escravos nas cidades, bem como a fundação de redes de solidariedade para auxílio dos mais necessitados. Questões relacionadas à resistência cultural deste segmento social são resumidas à capoeira e à religiosidade. Sobre os indígenas, não há nenhum tipo de abordagem. No restante do livro, que perpassa o fim da "República Velha", pela Era Vargas, Regime Militar e pela Redemocratização, os temas trabalhados giram em torno de aspectos políticos e econômicos principalmente, com espaços pontuais nos quadros "explorando o tema" para os sujeitos históricos, panorama social, cultura e ciências. Em nenhum destes quadros, na versão do PNLD 2014/2016 a temática indígena é representada, nem mesmo de forma indireta.

A não abordagem da temática não se deve por falta de fontes históricas, pois, como demonstram inúmeros estudos, a questão indígena movimentou o cenário político e social de todo o século XX. Logo no início do século, mais precisamente em 1910, o governo federal, pressionado pelas denúncias internacionais de extermínio de indígenas ${ }^{10}$, vai criar um órgão governamental que ficará responsável

9 Lembrando que a data de publicação da coletânea PNLD 2014/2016 é 2012 e da coletânea PNLD 2017/2019 é 2015.

${ }^{10}$ As narrativas de confrontos entre populações indígenas e frentes de expansão agrícolas se tornaram corriqueiras em jornais e periódicos do início do século XX. As investidas dos Kaingang 
pela política indigenista no país: o Serviço de Proteção aos Índios (SPI ${ }^{11}$. Este fato alcançou grande repercussão nacional e está muito bem documentado por diversos autores (SANTOS, 1970; 1973; RIBEIRO, 1986; SOUZA LIMA, 1995; WITTMANN, 2007; FREIRE, 2011). Seria importantíssimo que as relações estabelecidas entre as frentes de imigração/migração e as populações indígenas fossem abordadas no livro, pois contribuiria para uma análise mais completa da situação fundiária e das relações étnico-raciais no contexto da expansão das fronteiras agrícolas no Brasil.

O SPI ficou responsável pelas ações de proteção e assistência às populações indígenas entre 1910 e 1967, quando, após denúncias de corrupção e violências contra indígenas, acaba sendo extinto e substituído pela Fundação Nacional do Índio (FUNAI), já durante o Regime Militar (1964-1985). O período, assinalado por projetos desenvolvimentistas e autoritários, marcou profundamente a história brasileira e indígena. Momentos históricos importantes como o denominado "milagre econômico", que deram vazão à construção de vias de conexão entre as regiões, como a estrada transamazônica, a abertura de novas frentes agropastoris no centro-oeste e norte, grandes projetos hidrelétricos, tiveram impactos substanciais para muitas etnias indígenas (DAVIS, 1978; VALENTE, 2017). A própria perseguição a lideranças indígenas que confrontavam os interesses do regime são ignoradas nesta versão. São fatos bastante documentados por meio de fotografias, vídeos, jornais, livros e outras publicações ${ }^{12}$ que possibilitam a construção de sínteses didáticas claras e essenciais para os livros escolares, especialmente

nas fazendas cafeeiras e nas frentes de trabalho da estrada de ferro Noroeste do Brasil, no estado de São Paulo impulsionaram uma reação severa por parte de autoridades políticas e econômicas da região. No sul do Brasil, em SC, eram os Botocudos (Xokleng), considerados ameaças aos lotes coloniais, sendo, por isso, perseguidos, ameaçados e mortos por bugreiros contratados por políticos e agências de colonização. Essas ocorrências só mereceram atenção do governo brasileiro quando tiveram repercussão internacional, por meio das denúncias do naturalista tcheco Alberto Vojtech Friĉ, no XVI Congresso de Americanistas de Viena em 1908 (SANTOS, 1970; WITTMANN, 2007).

11 Inicialmente denominado Serviço de Proteção aos Índios e Localização dos Trabalhadores Nacionais (SPILTN), foi aprovado e publicado através do Decreto n. 8.072, de 20 de junho de 1910, e efetivamente regulamentado pelo Decreto n. 9.214, de 15 de dezembro de 1911. Seu primeiro Diretor Geral foi o Marechal Candido Mariano Rondon.

12 Há inúmeros autores que dedicam capítulos ou obras inteiras a respeito do tema. Para maiores detalhes, ver: DAVIS, Shelton. Vítimas do milagre: o desenvolvimento e os índios do Brasil. Rio de Janeiro: Zahar Editores, 1978; VALENTE, Rubens. Os fuzis e as flechas: história de sangue e resistência indígena na ditadura. São Paulo: Cia das Letras, 2017. 
em uma coletânea que demonstra preocupação em explorar os temas a partir de diferentes fontes e abordagens.

A própria constituição de 1988, que trouxe importantes avanços no tocante aos direitos indígenas ${ }^{13}$ é subdimensionada no livro. São dedicados apenas dois pormenores para ilustrar este importante momento da história brasileira. Num deles, o destaque é dado à imagem das costas de três indígenas que assistem aos discursos de parlamentares no Congresso Nacional durante a cerimônia de promulgação da Constituição (PELLEGRINNI; DIAS; GRINBERG, 2012c, p. 210). O segundo refere-se a um trecho no qual é destacado que os indígenas "[...] tiveram assegurado o direito às terras que tradicionalmente ocupavam" (PELLEGRINNI; DIAS; GRINBERG, 2012c, p. 215). Resumir a presença indígena a esses pequenos elementos contribui para diminuição de seu protagonismo também na montagem do texto constitucional. Durante a Assembleia Constituinte de 1987/88, foram elencadas importantes questões que depois acabaram incorporadas à carta magna, como: reconhecimento das organizações sociais, costumes e tradições, inalienabilidade das terras que ocupam, usufruto exclusivo dos recursos naturais, obrigatoriedade da União pela demarcação das terras, entre outros. A diversidade cultural e as representações socioculturais indígenas são deixadas na invisibilidade nesta versão do livro didático.

É possível observar, felizmente, que há um avanço conceitual na versão do PNLD 2017/2019 em relação à anterior. A questão dos direitos e o papel dos sujeitos históricos indígenas são elencados no subcapítulo dedicado à análise do panorama social do Brasil no mundo contemporâneo, quando se observa um real destaque para a temática indígena. Embora não faça uma discussão sobre a diversidade étnico-racial, a perspectiva dos direitos indígenas é bem representada através da citação do artigo 231 da CF88, bem como aponta argumentos dos grupos políticos e ideológicos que militam contrários e a favor dos referidos direitos.

No panorama da história recente, destaca-se a apresentação de um mapa com a representação das áreas habitadas por indígenas no território nacional e de

\footnotetext{
${ }^{13} \mathrm{Na} \mathrm{CF} / 88$, um capítulo é dedicado aos povos indígenas. Destaca-se o artigo 231 do capítulo XIV, onde "são reconhecidos aos índios sua organização social, costumes, línguas, crenças e tradições, e os direitos originários sobre as terras que tradicionalmente ocupam, competindo à União demarcá-las, proteger e fazer respeitar todos os seus bens" (BRASIL, 1988).
} 
um cartaz sobre o vestibular específico para indígenas, promovido em 2014 pela Universidade do Centro Oeste do Paraná (UNICENTRO), que remete à presença indígena no ensino superior no Brasil (PELLEGRINNI; DIAS; GRINBERG, 2015c, p. 316-7). Importante também ressaltar a evidência do protagonismo indígena na história quando, no quadro "o sujeito na história", é apresentado o cacique Ângelo Kretã, importante liderança Kaingang que participou ativamente, entre o final dos anos 1970 e início dos anos 1980, do movimento de retomada de áreas indígenas invadidas por posseiros e madeireiros nos estados do Paraná, Santa Catarina e Rio Grande do Sul (PELLEGRINNI; DIAS; GRINBERG, 2015c, p. 316-7).

Embora ainda insuficiente para abarcar a complexidade e a dinâmica da temática indígena, o fato de realçar temas como a luta pela terra, a educação escolar e universitária e a distribuição geográfica das terras demarcadas no território brasileiro, a versão do PNLD 2017/2019 retira os indígenas da quase invisibilidade promovida pela versão anterior. É um avanço, sem dúvida, que contribui para desmistificar a perspectiva da extinção e/ou assimilação dos povos originários e avançar no reconhecimento de seu protagonismo histórico.

\section{CONSIDERAÇÕES FINAIS}

Nos últimos anos tem-se evidenciado um grande movimento de autovalorização étnica e cultural por parte das populações indígenas no contexto latino-americano. No caso do Brasil, o fenômeno perpassa desde movimentos de etnogênese até as pautas reivindicatórias por maior autonomia nos processos de escolarização específicos e diferenciados. No campo das ciências humanas, caminha a valorização das cosmovisões de cada povo e o protagonismo dos próprios sujeitos indígenas enquanto agentes da mudança. A Nova História Indígena, neste sentido, contribuiu significativamente para desvelar novos olhares e novas interpretações sobre os povos indígenas no Brasil, ao compreender os mesmos não como objetos de estudo, mas como protagonistas e agentes de sua própria história. Quanto ao papel do Estado, houve uma ampliação em termos de decretos, leis, estatutos, projetos e outras ações que fornecem subsídios aos autores e autoras de livros didáticos para suplantarem as narrativas clássicas, insuficientes para compreensão escolar sobre as dinâmicas sociais, culturais, políticas e cosmológicas que envolvem os povos indígenas. 
Em termos de conteúdos para a educação no contexto das relações étnico-raciais, é preciso destacar que a coletânea Vontade de Saber: História apresenta um avanço significativo no tocante à história da África, dos povos africanos e dos afro-brasileiros. No exemplar do 70 ano, por exemplo, são encontradas referências aos reinos e impérios africanos existentes entre os séculos VI e XVI; no volume do 8 o ano é apresentada a África no contexto do século XIX ainda com seus impérios, mesmo com o desenvolvimento do processo de colonização europeia; no tocante ao 9o ano, são observados os processos de independência dos estados africanos no século XX. Há, nesta perspectiva, uma observância das orientações presentes nas Diretrizes Curriculares Nacionais para a Educação das Relações Étnico-Raciais e para o Ensino de História e Cultura Afro-Brasileira e Africana. A mesma atenção, no entanto, não é observada quando se analisa o conteúdo referente à temática indígena.

Não se trata aqui, obviamente, de afirmar que a abordagem referente à história africana e afro-brasileira mereceria menos espaço que história e cultura indígena. Pelo contrário, ambas são fundamentais para a ampliação do leque conceitual dos estudantes acerca das diferentes tradições e origens do povo brasileiro e para o rompimento de uma tradição de ensino de História escancaradamente eurocêntrica. O que se propõe é que haja uma ampliação em termos de quantidade e qualidade no conteúdo de ambos os temas, como indicado pela Lei n. 11645/08, fornecendo subsídios que permitam superar as deficiências no ensino dos mesmos, marcado historicamente por abordagens genéricas e descontextualizadas. Somente com isso as literaturas didáticas podem efetivamente contribuir com o combate ao preconceito e a discriminação muitas vezes veiculadas em suas próprias páginas.

Ainda assim, não se pode cometer injustiças e afirmar categoricamente que na coletânea Vontade de Saber: História, as populações indígenas sejam apresentadas exclusivamente a partir de realidades fixas e imutáveis ou com sua pluralidade completamente apagada. Também não há em seu conteúdo a vinculação clássica do índio exótico e romântico, em situação de assimilação e consequente extinção enquanto populações social e culturalmente distintas. No mesmo sentido, não existe um completo silenciamento ou ignorância a respeito das demandas indígenas no tempo presente. Porém, não se pode negligenciar o fato preocupante de que uma pesquisa desenvolvida encontrou, mais de 10 anos 
após a promulgação da Lei n. 11.645/08, uma defasagem considerável em relação aos conteúdos relativos ao ensino da História e Cultura Indígena em materiais didáticos distribuídos em 18 das 25 escolas públicas municipais de Florianópolis. Deste modo, conclui-se que o conteúdo da coletânea em questão é insuficiente para o ensino de uma história reflexiva e problematizadora sobre os indígenas no Brasil.

As sugestões e indicações neste artigo têm o intuito, além de promover o preenchimento de algumas lacunas históricas observadas na coletânea em questão, também contribuir para que haja um avanço nos tópicos já existentes. Embora se compreenda que o livro didático não seja o único e exclusivo instrumento utilizado pelos professores e professoras em suas aulas, em muitos casos ele é fundamental, inclusive condicionando atividades e estratégias pedagógicas. Exatamente por esse caráter, se o texto didático puder suscitar novos questionamentos, debates e reflexões que possibilitem aos estudantes perceberem as populações indígenas como presentes e atuantes nas diferentes esferas da sociedade, ele já terá correspondido tanto aos intuitos educativos e políticos, quanto aos valores humanos tão necessários a uma sociedade democrática e plural.

\section{REFERÊNCIAS}

ALMEIDA, M. R.C. A atuação dos indígenas na história do Brasil: revisões historiográficas. In: Revista Brasileira de História, São Paulo, v. 37, n. 75, 2017. p. 17-38. Disponível em: http://dx.doi.org/10.1590/1806-93472017v37n75-02

ALMEIDA, M. R.C. Os índios na história do Brasil. Rio de Janeiro: FGV, 2010.

BANIWA, G. S. L. Movimentos e políticas indígenas no Brasil contemporâneo. In: Revista Tellus, Campo Grande, ano 7, n. 12, 2007. p. 127-46. Disponível em: http://www.gpec. ucdb.br/projetos/tellus/index.php/tellus/article/view/136. Acesso em: 2 dez. 2020.

BITTENCOURT, C. M. F. Ensino de história: fundamentos e métodos. 5. ed. São Paulo: Cortez, 2018.

BORELLI, S. H. S. Os kaingang no estado de São Paulo: constantes históricas e violência deliberada. In: MONTEIRO, J. M.; RANGEL, L. H.; ANDRADE, L. M. M.; LUIZ, M. L. M.; GOMES, R. S.; GUERRIERO, S.; BORELLI, S. H. S. Índios no estado de São Paulo: resistência e transfiguração. São Paulo: Yankatu, 1984. 
Ensino história indígena em livros didáticos: problematizações a partir de uma coletânea distribuída na rede municipal de ensino de Florianópolis, SC

BRASIL. Ministério da Educação. PNLD 2017/2019. Brasília-DF, 2016.

BRASIL. Ministério da Educação. Diretrizes Operacionais para a implementação da história e das culturas dos povos indígenas na Educação Básica, em decorrência da Lei n. 11.645/2008. Brasília-DF, 2015.

BRASIL. Lei n. 11.645, de 10 de março de 2008. Obrigatoriedade da temática "História e Cultura Afro-Brasileira e Indígena". Brasília-DF, 2008. Disponível em: http://www.planalto. gov.br/ccivil_03/_Ato2007-2010/2008/Lei/L11645.htm. Acesso em: 12 mar. 2019.

BRASIL. Ministério da Educação. Diretrizes Curriculares Nacionais para a Educação das Relações Étnico-raciais e para o Ensino de História e Cultura Afro-Brasileira e Africana. Brasília-DF, 2004.

BRASIL. Lei n. 10.639, de 9 de janeiro de 2003. Obrigatoriedade da temática "História e Cultura Afro-Brasileira". Brasília-DF, 2003. Disponível em: http://www.planalto.gov.br/ ccivil_03/leis/2003/l10.639.htm. Acesso em: 12 mar. 2020.

BRASIL. Assembleia Nacional Constituinte. Constituição da República Federativa do Brasil. Brasília-DF, 1988.

CAIMI, F. E. O livro didático de história e suas imperfeições: repercussões do PNLD após 20 anos. In: ROCHA, H. A. B.; REZNIK, L.; MAGALHÃES, M. S. (Org.). Livros didáticos de história: entre políticas e narrativas. 1. ed. Rio de Janeiro: FGV, 2017. p. 23-45.

COELHO, M. C.; COELHO, W. N. B. O ensino de história e os desafios da diversidade: a conformação da consciência histórica nos processos de implementação da Lei 10639/2003. In: ROCHA, H.; MAGALHÃES, M.; GONTIJO, R. O ensino de história em questão: cultura histórica, usos do passado. Rio de Janeiro: FGV, 2015. p. 283-304.

CUNHA, M. C. (Org.). História dos índios no Brasil. São Paulo: Companhia das Letras, 1992.

DAVIS, S. Vítimas do milagre: o desenvolvimento e os índios do Brasil. Rio de Janeiro, Zahar Editores, 1978.

DICKIE, M. A. S. Levi Strauss e os fios da história. In: GROISMAN, A. et al. Antropologia em primeira mão. Florianópolis: UFSC, 2012.

FLORIANÓPOLIS (Estado). Secretaria Municipal de Educação. Diretrizes Curriculares para a Educação Básica da Rede Municipal de Ensino de Florianópolis/SC. Florianópolis, 2015. Disponível em: http://www.pmf.sc.gov.br/arquivos/arquivos/pdf/25_05_2015_13.21.19. a8cfbc1ba45502447185ee928a98ce06.pdf. Acesso em: 13 abril 2019. 
FONSECA, S. G. Didática e prática de ensino de História: experiências, reflexões e aprendizados. Campinas: Papirus, 2012.

FREIRE, C. A. R. (Org.). Memória do SPI: textos, imagens e documentos sobre o Serviço de Proteção aos Índios (1910-1967). Rio de Janeiro: FUNAI, 2011.

GRUPIONI, L. D. B. Livros didáticos e fontes de informações sobre as sociedades indígenas no Brasil. In: SILVA, A. L.; GRUPIONI, L. D. B. (Org.). A temática indígena na escola: novos subsídios para professores de 1으 e 2o graus. São Paulo: Global, 1995 p. 481-525.

MONTEIRO, J. Tupi, tapuias e historiadores: estudos de História Indígena e Indigenismo. 2001. Tese (Livre Docência) - Universidade Estadual de Campinas, Campinas, SP, 2001.

MONTEIRO, J. Negros da terra: índios e bandeirantes nas origens de São Paulo. São Paulo: Companhia das Letras, 1994.

MUNDURUKU, D. O caráter educativo do movimento indígena brasileiro (1970-1990). São Paulo Paulinas, 2012.

OLIVEIRA, J. P. Ensaios de Antropologia Histórica. Rio de Janeiro: UFRJ, 1999.

PELLEGRINNI, M. C.; DIAS, A. M.; GRINBERG, K. Vontade de saber - história. 70 ano. 2. ed. São Paulo: FTD, 2012a.

PELLEGRINNI, M. C.; DIAS, A. M.; GRINBERG, K. Vontade de saber - história. 8o ano. 2. ed. São Paulo: FTD, 2012b.

PELLEGRINNI, M. C.; DIAS, A. M.; GRINBERG, K. Vontade de saber - história. 9o ano. 2. ed. São Paulo: FTD, 2012c.

PELLEGRINNI, M. C.; DIAS, A. M.; GRINBERG, K. Vontade de saber - história. 7o ano. 3. ed. São Paulo: FTD, 2015a.

PELLEGRINNI, M. C.; DIAS, A. M.; GRINBERG, K. Vontade de saber - história. 8o ano. 3. ed. São Paulo: FTD, 2015b.

PELLEGRINNI, M. C.; DIAS, A. M.; GRINBERG, K. Vontade de saber: história. 9 Ano. 3. ed. São Paulo: FTD, 2015c.

PEREGALLI, H. A América que os europeus encontraram. São Paulo: Atual, 1994. 
Ensino história indígena em livros didáticos: problematizações a partir de uma coletânea distribuída na rede municipal de ensino de Florianópolis, SC

PINSKY, J.; PINSKY, C. B. O que e como ensinar: por uma história prazerosa e consequente. In: KARNAL, L. (Org.). História na sala de aula: conceitos, propostas e práticas. 6. ed. São Paulo: Contexto, 2018. p. 17-36.

RIBEIRO, D. Os índios e a civilização: a integração das populações indígenas no Brasil moderno. 5. ed. Petrópolis: Vozes, 1986.

RODRIGUES, R. A. Cenários da ocupação guarani na calha do Alto Paraná: um estudo etnoarqueológico. 2001. Dissertação (Mestrado em Arqueologia) - Universidade de São Paulo, São Paulo, SP, 2001.

SANTIAGO, A. R. F. A viabilidade dos PCNs como política pública de intervenção no currículo escolar. In: REUNIÃO ANUAL DA ASSOCIAÇÃO NACIONAL DE PÓS-GRADUAÇÃO [ANPED], 23., 24-28 set. 2000, Caxambu. Anais [...]. Rio de Janeiro: ANPED, 2000. Disponível em: https://www.anped.org.br/biblioteca/item/viabilidade-dos-pcn-como-politica-publicade-intervencao-no-curriculo-escolar. Acesso em: 10 dez. 2020.

SANTOS, S. C. Índios e brancos no sul do Brasil: a dramática experiência Xokleng. Florianópolis: Edeme, 1973.

SANTOS, S. C. A integração do índio na sociedade regional: a função dos postos indígenas em Santa Catarina. Florianópolis: UFSC, 1970.

SILVA, A. L.; GRUPIONI, L. D. B. A temática indígena na escola: novos subsídios para professores de 1으 e 2ำ graus. Brasília: MARI/MEC/UNESCO, 1995.

SOUZA LIMA, A. C. Um grande cerco de paz: poder tutelar, indianidade e formação do estado no Brasil. Petrópolis, Vozes, 1995.

SPOSITO, F. Nem cidadãos, nem brasileiros: indígenas na formação do estado nacional brasileiro e conflitos na província de São Paulo. 2006. Dissertação (Mestrado em História Social) Universidade de São Paulo, São Paulo, SP, 2006.

VALENTE, R. Os Fuzis e as flechas: história de sangue e resistência indígena na ditadura. São Paulo: Companhia das Letras, 2017.

VARNHAGEN, F. A. História Geral do Brasil [1854] 7. ed. São Paulo/Belo Horizonte: Edusp/ Itatiaia, 1980.

WITTMANN, L. T. O vapor e o botoque: imigrantes alemães e índios Xokleng no Vale do Itajaí/SC (1850-1926). Florianópolis: Letras Contemporâneas, 2007. 


\section{Sobre o autor:}

Sandor Bringmann: Mestre e doutor em História Cultural pela Universidade Federal de Santa Catarina (UFSC). Graduado em História pela Universidade Federal de Santa Maria (UFSM). Professor Adjunto do Departamento de Metodologia de Ensino na UFSC. Coordenador do Programa de Pós-Graduação em Ensino de História (ProfHistória/UFSC).E-mail: s_bringmann@yahoo.com.br, ORCID: https://orcid.org/0000-0002-3866-0026

Recebido em: 03/06/2020

Aprovado para publicação em: 08/03/2021 